\title{
STUDIES ON A NEW HIGH-INTENSITY LOW-EMISSION BURNER
}

\author{
SUDARSHAN KUMAR, P. J. PAUL AND H. S. MUKUNDA \\ Combustion Gasification and Propulsion Laboratory \\ Department of Aerospace Engineering \\ Indian Institute of Science \\ Bangalore 560 012, India
}

\begin{abstract}
This paper presents computational and experimental results on a new burner configuration with a mild combustion concept with heat release rates up to $10 \mathrm{MW} / \mathrm{m}^{3}$. The burner configuration is shown to achieve mild combustion by using air at ambient temperature at high recirculation rates ( 250\%-290\%) both experimentally and computationally. The principal features of the configuration are: (1) a burner with forward exit for exhaust gases; (2) injection of gaseous fuel and air as multiple, alternate, peripheral highspeed jets at the bottom at ambient temperature, thus creating high enough recirculation rates of the hot combustion products into fresh incoming reactants; and (3) use of a suitable geometric artifice-a frustum of a cone to help recirculation. The computational studies have been used to reveal the details of the flow and to optimize the combustor geometry based on recirculation rates. Measures, involving root mean square temperature fluctuations, distribution of temperature and oxidizer concentration inside the proposed burner, and a classical turbulent diffusion jet flame, are used to distinguish between them quantitatively. The system, operated at heat release rates of 2 to $10 \mathrm{MW} / \mathrm{m}^{3}$ (compared to 0.02 to $0.32 \mathrm{MW} / \mathrm{m}^{3}$ in the earlier studies), shows a $10-15 \mathrm{~dB}$ reduction in noise in the mild combustion mode compared to a simple open-top burner and exhaust $\mathrm{NO}_{x}$ emission below $10 \mathrm{ppm}$ for a $3 \mathrm{~kW}$ burner with $10 \%$ excess air. The peak temperature is measured around $1750 \mathrm{~K}$, approximately $300 \mathrm{~K}$ lower than the peak temperature in a conventional burner.
\end{abstract}

\section{Introduction}

Development of a system with high efficiency and low pollutant emissions for a better environment and better energy resource management is continuing to be pursued by the combustion community. Many techniques, such as flame cooling, staged combustion, reburning, and exhaust gas recirculation, are proposed to reduce $\mathrm{NO}_{x}$ emissions [1]. The exhaust gas recirculation for $\mathrm{NO}_{x}$ reduction is drawing interest because of its promising features [1-6]. In this method, combustion products are recirculated and mixed into the fresh incoming fuel and air streams. This reduces the concentration of the reactants, thereby reducing the reaction rates avoiding the formation of sharp zones of high temperatures in the combustion chamber [1]. When recirculation rates are below $30 \%$, the flames are stable at all temperatures. There also exists another stable combustion mode when the recirculation rates are very high and temperatures are higher than the autoignition temperature of the fuel. This stable mode of combustion is termed as flameless combustion or mild combustion [1-4]. The key approach to reduce $\mathrm{NO}_{x}$ emission in this method is by reducing the thermal $\mathrm{NO}_{x}$ formation rate, directly dependent on the distribution of temperature and its fluctuations in the combustion process $[7,8]$.
Wunning and Wunning [1] established the flameless combustion in highly recirculating combustion chamber and proposed low $\mathrm{NO}_{x}$ and noise emission burners for industrial applications through the use of high-inflow air temperatures. The high speed jets of preheated air and methane (fuel) entrain large quantities of combustion products and attain the autoignition temperature before the reaction starts between fuel and oxidizer. Recuperation and/or regeneration are used to preheat the incoming air to high temperatures. In several of these studies $[2,4,5]$, reverse-flow geometry has been used to create the flameless combustion phenomenon; the aerothermochemical features are mapped at high recirculation rates to quantify the operational characteristics of the burner under different operating conditions in premixed (lean and rich) and non-premixed regimes. Experiments indicated that flameless combustion falls in a stirred reactor regime where simultaneous ignition and extinction phenomena are absent [2]. Weber et al. [9] have shown in their work that both air and fuel entrain considerable amounts of combustion products, and combustion proceeds at rates lower than in conventional burners. A recent study by Katsuki and Hasegawa [10] indicates the need for highly preheated air for creating mild combustion, and this has been commented upon by Wunning, indicating that it would work even without 
TABLE 1

Summary of the previous work on mild combustion

\begin{tabular}{|c|c|c|c|c|c|c|}
\hline Ref. & Geometry & Fuel & $\begin{array}{l}\text { Heat release rate } \\
\qquad\left(\mathrm{kW} / \mathrm{m}^{3}\right)\end{array}$ & $\begin{array}{l}T_{\text {Air }} \\
(\mathrm{K})\end{array}$ & $\begin{array}{c}\mathrm{EINO}_{x} \\
(\mathrm{~g} / \mathrm{kg} \text { fuel })\end{array}$ & $\begin{array}{l}T_{\text {Operating }} \\
\quad(\mathrm{K})\end{array}$ \\
\hline [1] & Multipoint injection burner & Methane & Not known & $1073-1373$ & 2.19 & 1573 \\
\hline [2] & Reverse-flow geometry & Methane & $\sim 320$ & 773 & 0.27 & 1650 \\
\hline$[4,5]$ & Reverse-flow geometry & Methane & $\sim 180$ & 650 & 0.11 & 1650 \\
\hline$[10]$ & Regenerative burner & Natural gas & 23 & 1573 & 1.23 & Not known \\
\hline$[12]$ & High-heat intensity burner & LPG & 5000 & 300 & 0.35 & 1650 \\
\hline$[13]$ & Blue-flame burner at $(\phi=0.91)$ & Kerosene & Not known & 300 & 0.77 & 1750 \\
\hline
\end{tabular}

preheating. The authors [10], in response, hint further that this feature will be true in large systems not affected by heat losses leaving a residual position of non-clarity on the issue as to what happens for small power systems. The present work will answer the question in favor of Wunning's assertion by demonstrating mild combustion at low power level with high heat release rates using fuel and air at ambient temperature.

The heat release rates in the previous experiments $[2,4,5,7,11]$ are very small, varying from 23 to $\sim 320$ $\mathrm{kW} / \mathrm{m}^{3}$ as shown in Table 1 . It is the aim of the combustion system design to achieve high heat release rates while meeting the requirement of low emissions. The objective of current research is to develop a new burner with following features: (1) low chemical emissions and noise, (2) high heat

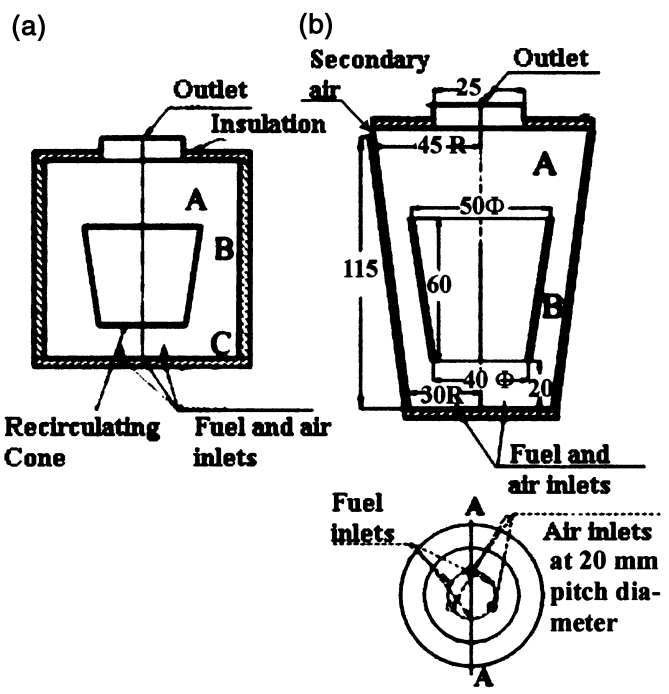

FIG. 1. The optimized burner configuration with its detailed dimensions. (a) Cylindrical configuration with central fuel and surrounding air; (b) modified configuration with alternate peripheral injection jets and secondary air. release rates $\left(2-10 \mathrm{MW} / \mathrm{m}^{3}\right)$, (3) wide operating range for different fuels, and (4) achieving mild combustion by using air and fuel at ambient temperatures. The optimization of burner configuration, preliminary predicted parameters, difference between diffusion jet flame and mild combustion, experimental design, and experimental results supporting the above features of the burner are presented in this paper.

\section{Computations}

The objective of the computational study is to optimize the burner configuration, quantify the recirculation rates and predict the flow field and combustion behavior of the burner. Commercially available CFD software CFX-Tascflow 2.10.00 [12] is used for the purpose. The fluid flow and combustion are simulated with three-dimensional Navier-Stokes equations, the standard $\kappa-\varepsilon$ model for turbulence, the energy equation, and mixture fraction and mixture variance equations. Turbulent combustion is modeled by laminar flamelet model at $300 \mathrm{~K}$ and 1 bar pressure for propane/air combustion. The various species $\mathrm{C}_{3} \mathrm{H}_{8}, \mathrm{O}_{2}, \mathrm{C}_{2} \mathrm{H}_{2}, \mathrm{C}_{2} \mathrm{H}_{4}, \mathrm{O}, \mathrm{CH}_{3}, \mathrm{CH}_{4}$, and $\mathrm{H}$ and other trace species are determined from flamelet libraries after solving the mixture fraction and variance equations. The geometry presents a sixfold symmetry about the vertical axis, with six alternate fuel and air injection nozzles. Therefore, computations are performed for one-sixth part of the burner with 120,000 grid points. To obtain a gridindependent result, a grid resolution study has been conducted with number of elements up to 150,000 . The results with respect to 150,000 were within $1 \%$ for all the meshes beyond 75,000 grid points.

\section{The Burner Configuration and Its Optimization}

Figures 1a and 1b show the geometry conceived and improved upon in this work through computational studies. The geometry consists of an insulated 


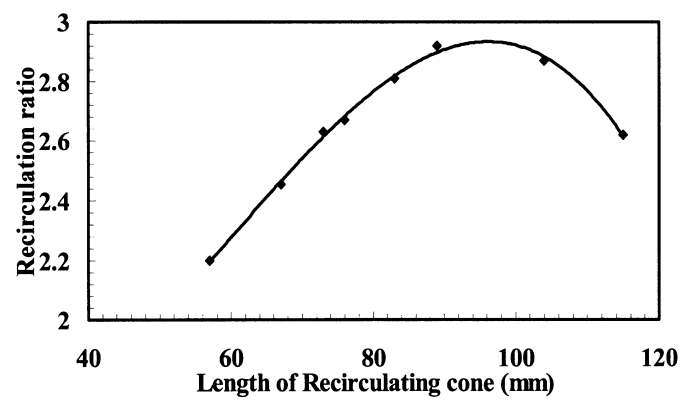

FIG. 2. Variation of recirculation rate variation with the length of the recirculating cone. The bottom position is fixed at $20 \mathrm{~mm}$ from injection plane, and the top length is varied to optimize the configuration.

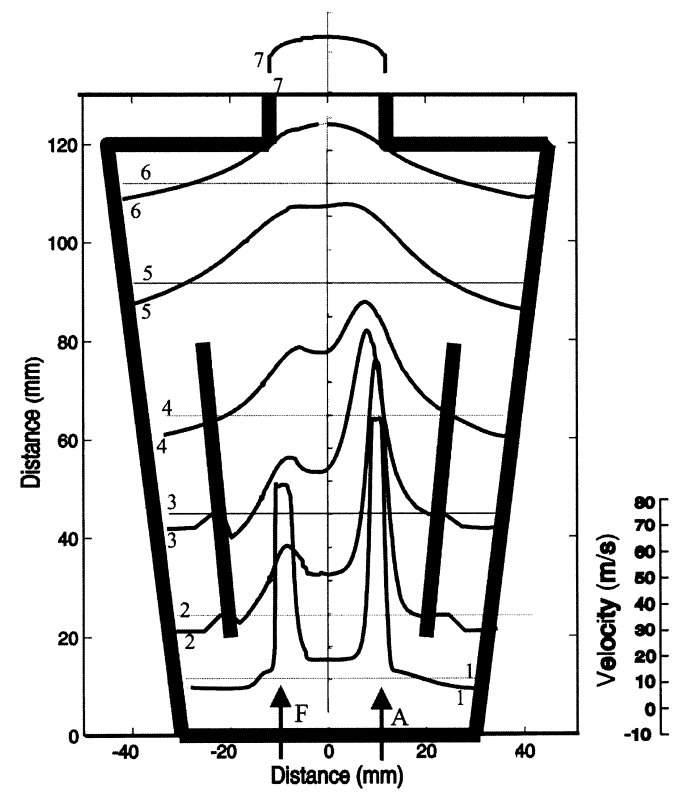

Fig. 3. Predicted velocity plots in the burner at different $x, y$ locations in the burner. The velocity scale is shown on the right side. The arrows indicate the position of fuel $(\mathrm{F})$ and air (A) injection.

cylinder (with $25 \mathrm{~mm}$ thick ceramic wool) with fuel and air injection from the bottom holes arranged around the periphery of a circle. The outlet is at the top. A thin conical object-frustum of a cone (made of metal here, but could be replaced by a ceramic material in practice) with space at the bottom and the top-is placed so that fluid can move from region A to region $\mathrm{C}$ through region $\mathrm{B}$ (refer to Fig. 1a). The size and shape of the conical object were settled by a large number of computational studies to determine the nature and the shape of the recirculation zones. In the first instance, the need for the cone itself was established when it was found that the fluid was recirculating in the top region with a small amount of fluid coming into the bottom area; this would not help in creating the favorable conditions for mild combustion. The presence of the conical object helped in drawing the hot gases from the top through the side region, the suction for which was provided by the high-speed jets of fuel and air arranged at the bottom. The recirculation ratio is the ratio of the amount of hot gases entering via $\mathrm{B}$ to the sum of the flow rates of fuel and air. The velocity and density profiles in the zone $\mathrm{B}$ are used to obtain the mass flow rate entering the bottom zone from the sides.

Initial trials with central fuel and surrounding air arrangement showed that the high-speed fuel jet easily escaped from the burner with incomplete combustion, and the recirculating products contained large oxidizer fraction. To achieve complete combustion and effective recirculation, combinations of central air, surrounding multiple fuel jets, and alternate peripheral air and fuel jets were explored. After this study [11], it was found that the required effective recirculation could be obtained with alternate peripheral jets (at $20 \mathrm{~mm}$ pitch diameter in this case, but suitable dimensions at other power levels); this also controlled the choice of the outlet diameter.

The computational study showed dead recirculating zones at the corners at the bottom. Hence, the geometry was further improved by eliminating the zones at $\mathrm{C}$ in Fig. 1a into a conical geometry as shown in Fig. 1b. A $11^{\circ}$ angle is selected for recirculating cone after a number of calculations aimed at reducing the dead zone [11]. Fig. 2 shows the variation of recirculation ratio with the length of the cone. The recirculation ratio goes through a maximum at $90 \mathrm{~mm}$ cone length and varies weakly up to $60 \mathrm{~mm}$. The final geometry realized is shown in Fig. $1 \mathrm{~b}$ that shows another interesting feature. The burner is provided with a facility to operate in staged combustion mode with slight excess air (limited to $10 \%$ of the total) supplied to reduce the CO emissions from the burner [11]. In this mode, $75 \%$ of the air is supplied through the primary jets coplanar to fuel jets, with the remaining air supplied in the top region. This burns up the residual CO.

Figure 3 shows the computed velocities in the burner for the case of $80 \mathrm{~mm}$ cone height. The fuel and air jets appear to lose their identity at a height just above the inner cone. The negative velocities are indicative of the reverse flow. Air flow dominates the flow field since the air-to-fuel momentum ratio is large, $\sim 18$.

\section{Mild Combustion and Current Burner}

On examination of the literature, it was noted that flameless combustion was defined qualitatively. It 
(a)

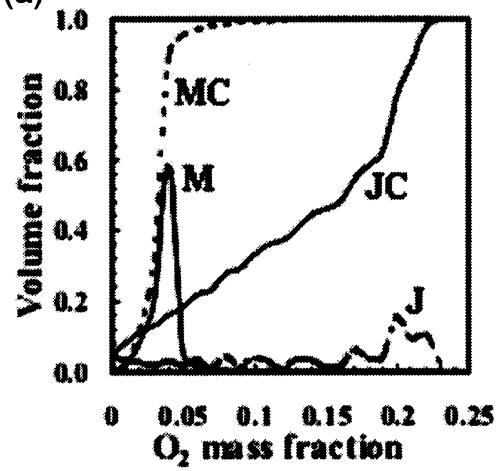

(c)

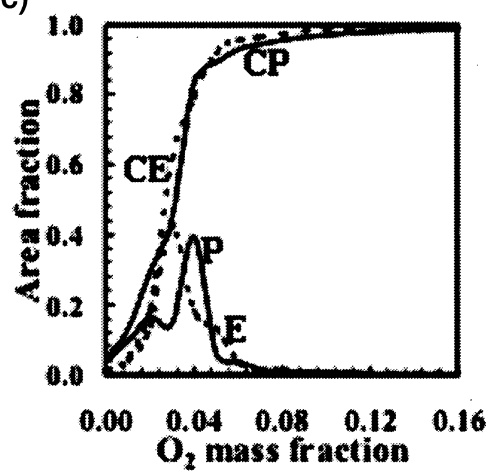

(b)

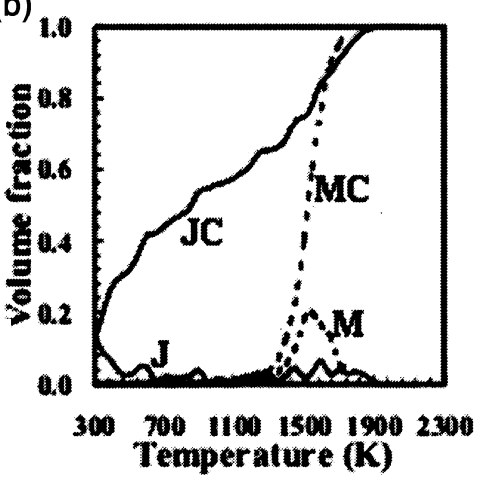

(d)

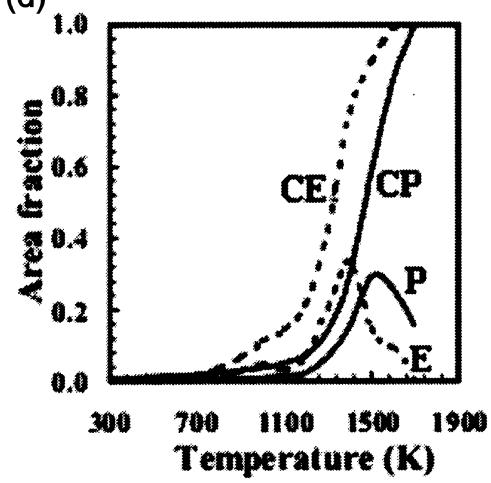

FIG. 4. Predicted volume fraction variation for (a) oxidizer mass fraction and (b) temperature. The volume is computed in $50 \mathrm{~K}$ temperature steps and $0.01 \mathrm{O}_{2}$ mass fraction steps. $\mathrm{M}$, local volume fraction variation for mild combustion burner; MC, cumulative distribution of volume fraction variation for mild combustion burner; J, local variation of volume fraction for jet flame; JC, cumulative distribution for jet flame. (c) Experimentally measured and predicted area fractions variation for $\mathrm{O}_{2}$ mass fraction and (d) temperature. E, experimentally measured; $\mathrm{CE}$, experimentally measured cumulative distribution; $\mathrm{P}$, predicted; $\mathrm{CP}$, predicted cumulative distribution. The temperatures and $\mathrm{O}_{2}$ mass fractions are measured in a two-dimensional plane across fuel and air jets, and then areas are evaluated in $100 \mathrm{~K}$ temperature steps and 0.01 oxidizer mass fraction steps.

was thought worthwhile to create a definition quantitatively to distinguish the mild combustion from classical combustion process. The construction of a criterion is attempted here. It is based on a mean square temperature variation in the flow field. It is inspired by the observation that in a classical flame, large spatial gradients of temperature occur, while in the case of mild combustion, process gradients are small. For comparison purposes, a turbulent propane jet flame with $R e \sim 14,000$, velocity $10 \mathrm{~m} / \mathrm{s}$, fuel jet diameter $7.5 \mathrm{~mm}$, and air coflow velocity $1 \mathrm{~m} / \mathrm{s}$ is used. The mean temperature, $T_{\text {mean }}$, is calculated by averaging it over the cell residence times. The cell residence times are chosen as against the cell volumes only to reflect the fact that emissions, particularly $\mathrm{NO}_{x}$, depend on the temperature-residence time relationship strongly $[8,9]$.

$$
T_{\text {mean }}=\int T d \tau_{r} / \int d \tau_{r}
$$

Somewhat similarly, the mean square temperature fluctuation over the combustor, $T^{\prime 2}$, is defined by

$$
T^{\prime 2}=\int\left(\frac{T-T_{\text {mean }}}{T_{\text {mean }}}\right)^{2} d V / \int d V
$$

Calculations have shown that in the present case, cell residence time-based $T_{\text {mean }}$ differs from the cell-volume-based $T_{\text {mean }}$ by less than $2 \%$. The mean temperature and its normalized root mean square variations are 1450 and $217 \mathrm{~K}$ for mild combustion burner and 1110 and $566 \mathrm{~K}$ for jet diffusion flame, respectively. Thus, the normalized spatial temperature variation is $15 \%$ for mild combustion and $51 \%$ for classical jet flame.

To further explore the differences, the temperature-volume behavior is extracted from the calculations. The volume fractions for every $50 \mathrm{~K}$ temperature step and 0.01 oxidizer fraction steps are integrated and plotted for both the cases. Figs. 4a 


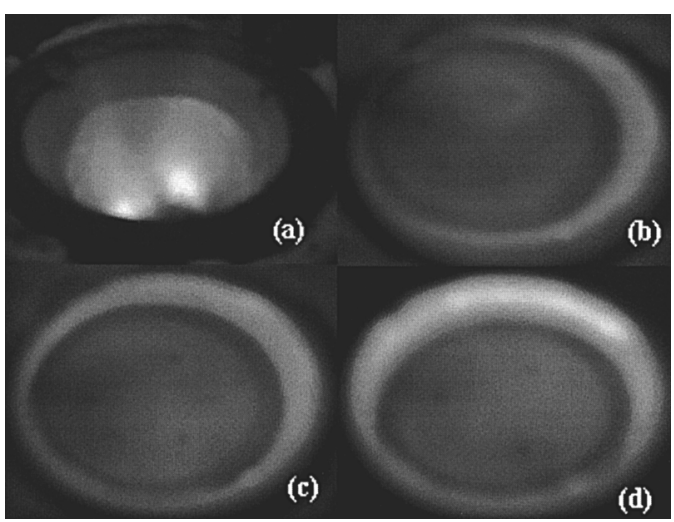

FIG. 5. Comparison between the conventional turbulent combustion (a) and mild combustion (b-d) in the same burner. The photographs are taken from the top of the burner.

and $4 \mathrm{~b}$ show the volume fraction variation with temperature and oxidizer fraction along with the cumulative variation. For the mild combustion burner, the temperature variation is $<350 \mathrm{~K}$ in $93 \%$ of the volume $(<200 \mathrm{~K}$ in $80 \%$ of the total volume). Oxidizer mass fraction $<0.07$ in $97 \%$ of the volume (less than 0.05 in $90 \%$ of the total volume, keeping in mind that burner is operated with $10 \%$ excess air). These are used to infer that the burner is operating in mild combustion mode. This also implies that the operation of the burner is near to a stirred reactor regime [2].

To seek comparisons with the experiments, the data on temperature and oxidizer obtained at a large number of points inside the burner at one section, $A-A$ (here) are processed using areas instead of volumes (as this was more straightforward to calculate), with similar results from the computations (presented in Figs. 4c and 4d). In one set of computations presented here, heat loss is allowed through the burner walls to fix boundary conditions similar to those that existed during the experiments. Fig. $4 \mathrm{c}$ shows that in 89 and $92 \%$ of the total area, the oxidizer mass fraction is less than 0.06 for computations and experiments. Although there is a difference in the $\mathrm{O}_{2}$ mass fraction prevalent in most of the combustion zone, the cumulative variation is almost similar for experiments and computations, indicated by curves CE and CP. Similar trends are seen in the cumulative temperature distribution, where the temperature variation is very small. The distribution for experiments and predictions is similar except for a difference of $\sim 100 \mathrm{~K}$ in the average temperature.

\section{Experiments}

The experimental setup consists of a $3 \mathrm{~kW}$ laboratory-scale burner with its diameters varying from
60 to $90 \mathrm{~mm}$ and height $120 \mathrm{~mm}$. A $3 \mathrm{~kW}$ thermal input and high heat release rate automatically sets up these dimensions. Air and fuel are injected from the six alternate peripheral jets at the bottom, as shown in Fig. $1 \mathrm{~b}$, at $20 \mathrm{~mm}$ pitch diameter. The combustion products are then allowed to go out through the outlet at the top. Typical mass flow rates used during the experiments are $0.067 \mathrm{~g} / \mathrm{s}$ of liquefied petroleum gas with a composition of $80 \%$ butane and $20 \%$ propane and $1.16 \mathrm{~g} / \mathrm{s}$ air with respective velocities approximately 60 and $79 \mathrm{~m} / \mathrm{s}$. The temperatures in the reaction zone measured with the help of $50 \mu \mathrm{m} \mathrm{Pt} / 13 \% \mathrm{Pt} / \mathrm{Rh}$ thermocouples. The results of temperature measurements are corrected for heat loss by conduction and radiation and heat gain by convection. The corrected temperatures are accurate to within $\pm 50 \mathrm{~K}$. Species $\left(\mathrm{NO}_{x}, \mathrm{CO}, \mathrm{CO}_{2}\right.$, $\mathrm{O}_{2}$, and $\mathrm{C}_{x} \mathrm{H}_{y}$ ) concentrations are measured in the reaction zone with the help of Quintox KM 9106 flue gas analyzer. The Quintox flue gas analyzer is composed of an $\mathrm{O}_{2}$ analyzer $(0 \%-25 \%$ range, $0.1 \%$ accuracy), a CO analyzer ( $0 \%-10 \%$ range, accuracy is $\pm 5 \%$ of the reading), a NO analyzer (0-5000 ppm, \pm 5 ppm accuracy), a $\mathrm{C}_{x} \mathrm{H}_{y}$ anlyzer (0-50,000 ppm), and $\mathrm{CO}_{2}$ analyzer. The analyzer is calibrated with a calibration gas to yield emissions on dry basis. The sample gases are continuously drawn from the combustion zone through a stainless-steel probe. The sample gases are immediately cooled with a cooling jacket provided on the sampling probe, $50 \mathrm{~mm}$ away from the probe suction point, dried, and then transferred to the analyzer. The obtained dry mole fractions are further converted to mass fractions on wet basis by including the water mass fraction. A Lutron SL-4001 sound level meter is used to measure the sound levels during the combustion experiments. The electric condenser microphone picks up the pressure fluctuations and displays the result in decibels. The typical range for the instrument is from 35 to $130 \mathrm{~dB}(0.1 \mathrm{~dB}$ resolution). The noise level measurements are taken at a point $30 \mathrm{~mm}$ distance from the outlet of the burner at the same plane.

\section{Experimental Results and Discussion}

The burner is operated with $10 \%$ excess air over a thermal range $1-5 \mathrm{~kW}$. Most of the results presented here are at the $3 \mathrm{~kW}$ level. Fig. 5 shows the distinction between the conventional open-top and mild combustion burners during their operation. The air injection holes at the bottom are clearly visible when the burner is operating in the mild combustion mode. A very weak flame is present everywhere in the system, bluish in color and barely visible. All the walls are red hot and glowing consistently. This weak bluish flame has been reported to occur when propane reacts with highly vitiated air at high temperatures [6]. The mild combustion state 


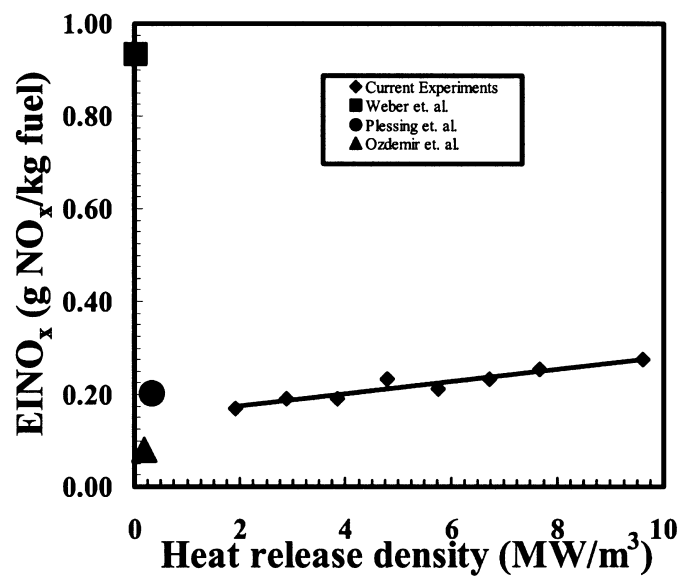

FIG. 6. Variation of $\mathrm{EINO}_{x}$ (normalized to $\mathrm{NO}_{2}$ ) with heat release intensity.

is achieved by a large recirculation of combustion products into fresh reactants, which increased the temperature of the reactants greater than the autoignition temperature of the fuel and simultaneously reduced the oxidizer concentration. Combustion is then followed by a slow reaction downstream.

The noise level measurement is taken at $1 \mathrm{~kW}$ power level for both conventional open-top and mild combustion burners. The reduction of the outlet size from conventional open top burner to $25 \mathrm{~mm}$ and proper positioning of the recirculating cone led to a noise reduction from 100 to $85 \mathrm{~dB}$, implying a reduction of $15 \mathrm{~dB}$. This noise reduction in comparison to conventional burner has been explained adequately in the literature as being due to the absence of pressure fluctuations due to the absence of ignition-extinction phenomena [13].

Figure 6 shows the experimentally measured $\mathrm{NO}_{x}$ emission index $\left(\mathrm{EINO}_{x}\right)$ variation with the heat release density $\left(\mathrm{MW} / \mathrm{m}^{3}\right)$. The experimentally measured $\mathrm{EINO}_{x}$ varies from 0.17 to $0.28 \mathrm{~g} / \mathrm{kg}$ fuel for a heat release density variation of $2-10 \mathrm{MW} / \mathrm{m}^{3}$. The $\mathrm{NO}$ emissions increase mildly with the increase in the power level. Although the emissions from the system are comparable to the earlier experiments $[2,4,5,14]$, the heat release rates are significantly (10-50 times) higher. Similar reductions of $\mathrm{NO}_{x}$ emissions are noted by Fujimori et al. [15] from lifted jet diffusion flames with high-temperature coflowing air, when the liftoff height exceeded the attached flame length. This decrease in $\mathrm{NO}_{x}$ emissions is attributed to decrease in the flame temperature at the flame base. The peak temperatures measured are below $1800 \mathrm{~K}$ in the combustion chamber; the NO formation through equilibrium thermal route is negligible [6]. The major contributors toward total NO formation appear to be superequilibrium, prompt, and $\mathrm{N}_{2} \mathrm{O}$ mechanisms.

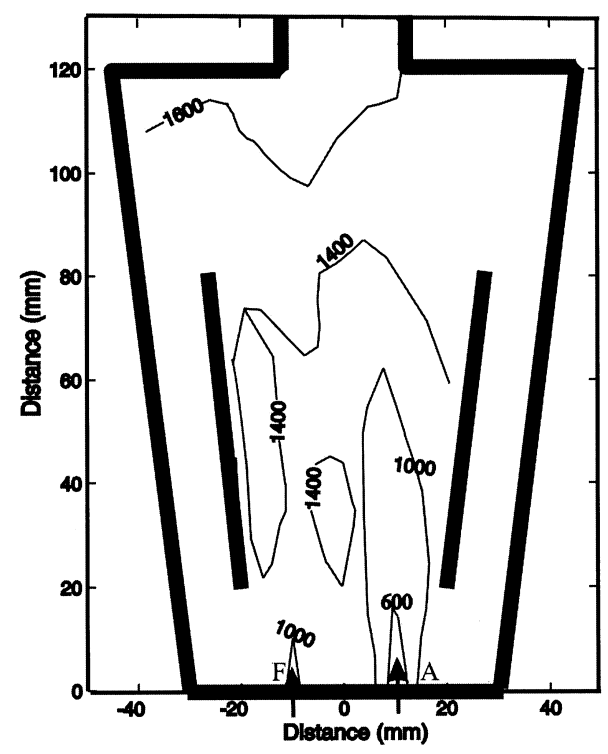

FIG. 7. Measured temperatures in the combustion zone (K).

Contours of the measured temperatures are shown in Fig. 7. The measured peak temperature is $\sim 1750 \mathrm{~K}$. The important point to note is that the reactants at ambient temperature are injected from the bottom reach a temperature of $1000 \mathrm{~K}$ within 10 and $50 \mathrm{~mm}$ from the point of the injection for fuel and air jets, respectively. During experiments, it is observed that the furnace walls and vitiated reactants are at a higher temperature, which is a requisite for the operation of a mild combustion burner. The lowtemperature gradients essentially indicate a small heat release rate over a large volume leading to small pressure fluctuations (noise levels) during the combustion.

The measured $\mathrm{CO}$ emissions are approximately $5000 \mathrm{ppm}$ and increased with the increase in the heat release density to $7000 \mathrm{ppm}$ at $10 \mathrm{MW} / \mathrm{m}^{3}$. These values are in the same range as the equilibrium value calculated by NASA-SP273 (4600 ppm) and $\sim 10,000 \mathrm{ppm}$ from blue-flame burners operated with kerosene and $10 \%$ excess air [14]. The average residence time of various species in the combustion zone, $132 \mathrm{~ms}$, is much higher than the reaction time; thus, the combustion products adjust themselves to the equilibrium composition. The measured $\mathrm{O}_{2}$ mole fractions in the combustion chamber are shown in Fig. 8. The peak $\mathrm{O}_{2}$ mole fraction falls to 0.06 at $40 \mathrm{~mm}$, due to strong mixing of combustion products into the air jet. At $60 \mathrm{~mm}$, the $\mathrm{O}_{2}$ concentration is almost constant reducing further downstream due to continuous weak reaction with the fuel. The exhaust $\mathrm{O}_{2}$ mole fraction is 0.02 . 

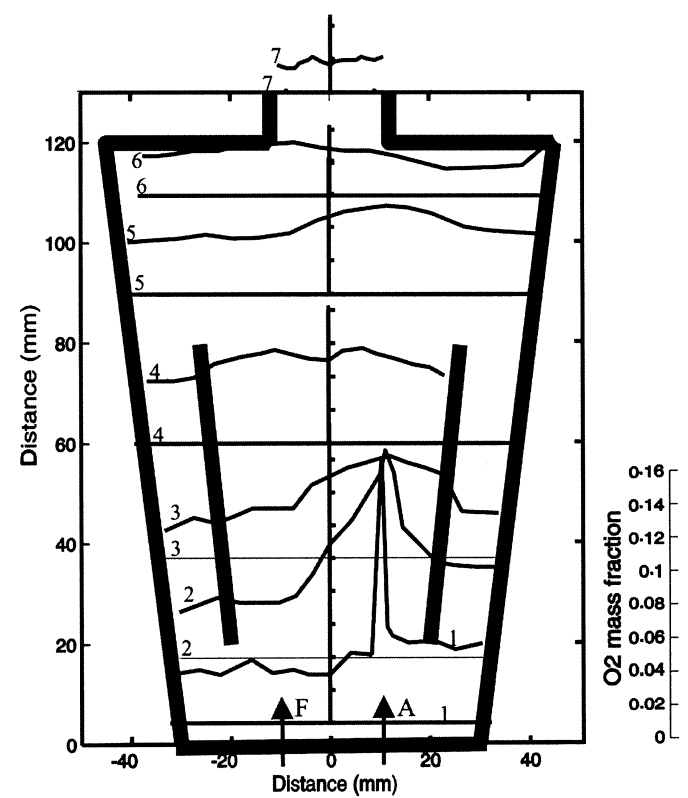

FIG. 8. $\mathrm{O}_{2}$ concentrations measured in the combustion chamber at different locations. The vertical scale is shown in the right-hand side. The numbers correspond to the horizontal axis and the curve drawn at a particular location.

\section{Conclusions}

The new burner configuration has been shown to achieve a mild combustion mode using reactants at ambient temperatures with high heat release rates and low emissions. The design of its features has been helped by aerothermochemical computations in conceiving a configuration to achieve mild combustion by using air and fuel at ambient temperature. The recirculation ratio, a function of recirculating cone and outlet dimensions, is about 2.8. The distribution of $\mathrm{O}_{2}$ and temperature is in the range of $0.002-0.007$ and $1550-1900 \mathrm{~K}$, respectively. The occurrence of low oxidizer concentration and high temperature in most of the volume is indicative of the operation of the burner in the mild combustion regime. This is further confirmed by evaluating a criterion based on the residence-time-based mean temperature and its mean square fluctuations. The temperature area and oxidizer area behavior for both experiments and computations are in a reasonable agreement.

The results of the emissions with the burner at $3 \mathrm{~kW}$ thermal input, fed with air and fuel at ambient temperatures, show NO emissions below $10 \mathrm{ppm}$ and $\mathrm{CO}$ emissions below $0.5 \%$ for a heat release rate of $\sim 6 \mathrm{MW} / \mathrm{m}^{3}$. The addition of secondary air helped in achieving the low $\mathrm{CO}$ emissions of $\sim 0.5 \%$. The NO emissions varied weakly with from 8 to $12 \mathrm{ppm}$ with the heat release rate $\left(2-10 \mathrm{MW} / \mathrm{m}^{3}\right)$. Similar trends in emissions are also observed when the burner is operated at stoichiometry. The outstanding low chemical emissions, high heat release rate, and low noise emission features strongly indicate the potential for use in industrial furnaces.

\section{REFERENCES}

1. Wunning, J. A., and Wunning, J. G., Prog. Energy Combust. Sci. 23(12):81-94 (1997).

2. Plessing, T., Peters, N., and Wunning, J. G., Proc. Combust. Inst. 27:3197-3204 (1998).

3. de Joannon, M., Langella, G., Beretta, F., Cavaliere, A., and Noviello, C., in Proceedings of Mediterranean Combustion Symposium, International Centre for Heat and Mass Transfer (ICHMT), Ankara, Turkey, 1999, pp. 347-360.

4. Ozdemir, B., and Peters, N., Exp. Fluids 30:683-695 (2001).

5. Coelho, P. J., and Peters, N., Combust. Flame 123:503518 (2001).

6. Bolz, S., Gupta, A. K., and Hasegawa, T. J., Energy Resources Technol. 121:209-216 (1999).

7. Turns, S. R., Prog. Energy Combust. Sci. 21:361-385 (1995).

8. Bowman, C. T., Proc. Combust. Inst. 24:859-878 (1992).

9. Weber, R., Orsino, S., Nicolas, L., and Verlaan, A., Proc. Combust. Inst. 28:1315-1321 (2000).

10. Katsuki, M., and Hasegawa, T., Proc. Combust. Inst. 27:3135-3146 (1998).

11. Sudarshan Kumar, Paul, P. J., and Mukunda, H. S., "High Intensity Low Emission Burners-Insights through Experiments and Computations," International Workshop on Modern Advances in Combustion, IIT Madras, India, August 31-September 1, 2001.

12. CFX-TASCflow Ver. 2.10.00, AEA Technology, U.K., July 2000.

13. Peters, N., Turbulent Combustion, Cambridge University Press, Cambridge, U.K., 2000, p. 230.

14. Prior, D. S., Swithenbank, J., and Felton, P. G., "The Stirred Reactor Modelling of a Low Pollution Liquid Fuelled Combustor," paper 77-51, AIAA Fifteenth Aerospace Sciences Conference, Los Angeles, January 1977.

15. Fujimoro, T., Riechelmann, D., and Sato, J., Proc. Combust. Inst. 27:1149-1155 (1998). 